\title{
IMPLICAÇÕES PEDAGÓGICAS NO INGRESSO DA CRIANÇA DE SEIS ANOS: AS ATIVIDADES FORMAIS NO PRIMEIRO ANO DO ENSINO FUNDAMENTAL.
}

\author{
Leonardo de Angelo Orlandi, Jéssika Naiara da Silva, José Milton de Lima, Márcia Regina Canhoto \\ de Lima
}

Universidade Estadual Paulista - FCT/UNESP. Grupo de Pesquisa Cultura Corporal: Saberes e Fazeres. Programa de Pós-Graduação em Educação, Presidente Prudente - SP. E-mail: leo angeloorlandi@hotmail.com

\section{RESUMO \\ Esta pesquisa partiu do pressuposto de que as atividades de estudo são uma importante fonte de humanização no contexto escolar e estabeleceu como objetivo central: acompanhar e interpretar as manifestações das crianças de seis anos acerca das atividades de estudo em uma turma de primeiro ano do Ensino Fundamental. A investigação de natureza qualitativa adotou como metodologia a abordagem descritivo-interpretativa e como procedimento metodológico a observação participante. Os resultados demonstram que o ingresso da criança de seis anos de idade de maneira abrupta gera alguns desconfortos e dificuldades de fruição nas atividades de estudo, uma vez que as condições sociais desse local tornam-se diferente daquele vivenciado outrora por elas na educação infantil. Por fim, a pesquisa aponta como necessidade a organização o processo educativo de forma integrada, respeitando igualmente os aspectos da atividade lúdica e das atividades de estudo, atendendo as especificidades e os modos de agir das crianças. \\ Palavras-chave: Estudo; Desenvolvimento; Infância; Ensino Fundamental; Criança. \\ PEDAGOGICAL IMPLICATIONS IN THE ADMISSION OF SIX-YEAR-OLD CHILD: FORMAL ACTIVITIES IN THE FIRST YEAR OF ELEMENTARY SCHOOL.}

\begin{abstract}
This research started from the assumption that the activities of study are an important source of humanization in the school context and established as central objective: to monitor and interpret the manifestations of children of six years of study activities in a class of first year of elementary school. Research of qualitative nature adopted as descriptive approach-interpretative methodology and as methodological procedure to participant observation. The results demonstrate that the admission of the child of six years old from abrupt way generates some discomfort and difficulties of fruition in the activities of study, since social conditions of this place become different from that experienced by them once in early childhood education. Finally, the research points out how the educational process organization need in an integrated manner, respecting also the aspect of playful activity and study activities, taking into account the specificities and the modes of action of children.
\end{abstract}

Keywords: Study; Development; Childhood; Elementary School; Child. 
As instituições de educação para crianças, de modo geral, tem considerado a infância como um dado universal e categoria natural. Tal contexto educacional pouco favorece a experiência com o conhecimento científico, tampouco com a cultura, seja esta entendida em sua dimensão de produção nas relações sociais cotidianas, ou como produção historicamente acumulada, presente na literatura, na música, na dança, no teatro, na brincadeira, enfim, na produção artística, histórica e cultural. No primeiro ano do Ensino Fundamental, o problema se acentua, principalmente pelo descompasso entre a redução do tempo de permanência da criança na Educação Infantil e sua ampliação no Ensino Fundamental, no qual são gerados contextos artificiais que obrigam as crianças a se adaptarem a situações pedagógicas até mesmo desprovidas de sentido para elas.

A partir da aprovação da Lei no 11.274 (BRASIL, 2006), o Ensino Fundamental passou a ter a duração de nove anos, com a inclusão obrigatória das crianças de seis anos nesse estágio da escolaridade. Nesse movimento abrupto, a implementação do ensino de nove anos e, consequentemente, a inserção de crianças com seis anos de idade no Ensino Fundamental transformam-se em verdadeiro tormento para aquelas que são obrigadas a se adaptar a situações e conteúdos que não lhes fazem sentido.

Na contramão das concepções adultocêntricas instaladas na educação brasileira, o Enfoque Histórico-Cultural concebe a criança como sujeito de sua atividade, capaz e competente na sua relação com o mundo (MELLO, 2007). Tal visão contribui para a formação de uma criança rica em possibilidades e capacidades, ativa e curiosa para se engajar no mundo da cultura, historicamente constituído. A infância, por sua vez, em lugar de ser entendida como um acontecimento estático, mergulhado em um vazio social, é vista como um fenômeno concreto e, por isso, mediatizado, num processo dialético, por temas sociais, culturais, políticos e econômicos do mundo contemporâneo.

Tomando por base essa forma de conceber a infância, com clareza da historicidade desse conceito que compreende a criança como sujeito da sua atividade, é preciso investir em pesquisas que propiciem a interlocução com a realidade educacional, contribuindo para a compreensão crítica dos fatores limitadores da aprendizagem e da formação da criança, bem como para a produção de conhecimentos que subsidiem a construção de práticas educativas de valorização da infância e de respeito à criança. Para tanto, nosso estudo contemplou as ações educacionais de estudo voltadas a criança e estabeleceu como objetivo principal, acompanhar e interpretar as manifestações das crianças de seis anos acerca das atividades de estudo em uma turma de primeiro ano do Ensino Fundamental, uma vez as instituições do Ensino Fundamental e 
educadores do primeiro ano sentem dificuldades na utilização de conteúdos que valorizem as especificidades da criança de seis anos.

\section{METODOLOGIA}

A investigação caracterizou-se como uma pesquisa de natureza qualitativa e adotou à metodologia do tipo descritivo-interpretativa sob o prisma da matriz epistemológica de corte histórico-cultural, que concebe a criança como um sujeito histórico e localizado culturalmente. Nesse contexto, o estudo considerou que a exposição das características do grupo pesquisado, do contexto e do fenômeno na sua relação com suas distintas variáveis, contribuiu para explicitar o problema da pesquisa e, ao mesmo tempo, permitiu analisar e compreender as manifestações das crianças na realidade vivenciada. A pesquisa de campo se desenvolveu em uma instituição de Ensino Fundamental da Rede Municipal de Educação de Presidente Prudente, tendo como universo um professor e 20 crianças do primeiro ano do Ensino Fundamental no ano letivo de 2012. No que tange ao dados, procuramos analisar, observar e interpretar situações rotineiras de estudo da turma investigada através do procedimento técnico da observação participante.

Assim, nossa expectativa foi, por intermédio desta pesquisa, contribuir para o entendimento dessa nova realidade da Educação Básica e na ampliação da compreensão das vivências infantis no contexto educacional aos seis anos de idade.

\section{RESULTADOS E DISCUSSÕES}

No avanço para a aprendizagem escolar ocorrem mudanças significativas em todas as esferas da vida da criança. Neste período surge o estudo como uma atividade obrigatória, responsável, que exige um trabalho organizado e sistemático.

De acordo com Elkonin (1998), a atividade de estudo aparece no momento em que a criança está inserida em um sistema de ensino sistematizado. Nesse período, a criança se depara com um contexto que exige atividades escolares mais sistematizadas, o estudo e os diferentes aspectos que o compõem, a organização escolar, como pontualidade, disciplina, responsabilidade e conteúdos extremamente diferentes do período pré-escolar.

Bozhovich (2003), aponta que esta atividade estabelece na criança a tarefa de assimilação consequente, planificada, de conhecimentos generalizados e sistematizados dos fundamentos da ciência, o que pressupõe uma estrutura de sua atividade cognoscitiva completamente distinta da infância pré-escolar. 
Nesse sentido, é consenso entre Vigotski (2003), Bozhovich (2003) e Davidov (2003) que essa etapa é caracterizada pela perda da espontaneidade infantil. Segundo Vigotski (2003), a razão da espontaneidade infantil encontra-se na falta de diferenciação suficiente da vida interior e da exterior. Isso quer dizer que as vivências das crianças, seus desejos, suas manifestações não se diferenciam na sua execução e não apresentam caráter formal. Em relação a este excerto, analisemos a seguinte situação:

Ben Dez estava brincando de avião com a borracha quando a professora the chamou à atenção: Ben Dez pare de brincadeira, agora é hora de estudar, se não vou te levar para a diretora aí você vai ver. (DIÁRIO DE CAMPO, DIA 12/08/2012)

Através desse exemplo podemos perceber que as exigências escolares começam a ser determinantes do comportamento das crianças, visto que o espaço para o brincar se faz em momentos parciais e segmentados. Em relação a essa questão Bozhovich (2003), aponta que em correspondência com a mudança de posição da criança e a aparição de uma nova atividade fundamental, o estudo, se reestrutura todo o curso cotidiano da vida da criança.

Nesse movimento, a qualidade do trabalho do escolar, assim como toda a sua conduta são valorizados pela escola, e esta apreciação influencia na atitude das pessoas que o circudam. Por outro lado, "el niño negligente en las obligaciones escolares, que no desea estudiar, es tratado com reprobación, [...] lo que introduce tensión en su vida, crea uma atmósfera de malestar y provoca ne él vivencias emocionales desagradables, que a veces resultan muy penosas" (BOZHOVICH, 2003, p. 10). Tal situação pode ser visualizada no seguinte episódio:

Patatá não estava querendo resolver os problemas que a professora estava passando no quadro e conversava incessantemente com seu colega ao lado. Nesse momento, a professora interferiu e disse a Patatá que era preciso resolver os problemas propostos. Após alguns momentos a professora volta e vê que Patatá não estava realizando as tarefas. Vendo que não estava realizando a tarefa, a professora começou a tratar Patatá de maneira ríspida e esse tratamento começou a gerar um mal estar em Patatá que afirmou posteriormente que estava cansado de tanto estudar e queria ficar mais sossegado. (DIÁRIO DE CAMPO, 20/08/2012)

Essa situação confirma as ideias de Mukhina (1995), que destaca que na situação do escolar seus estudos são uma atividade obrigatória e socialmente importante. Para a autora (1995) nessa situação a criança precisa responder ante o professor, ante a escola e ante sua família pelo cumprimento das atividades realizadas na escola.

Dessa forma, ao converter-se em escolar, a criança começa a empenhar/ocupar um novo lugar na sociedade, distinto daquele que ocupava enquanto pré-escolar. No entanto, segundo 
Bozhovich (2003, p. 10), conjuntamente com os novos deveres desta posição social, o escolar recebe novos direitos: "puede aspirar a una actitud seria por parte de los mayores hacia su tara docente; tiene derecho a un lugar de trabajo, al tiempo necesario para sus estudios, al silencio, al descanso, al tiempo libre". Outro ponto positivo na inserção da criança ao estudo planificado e sistemático, é a participação conjunta em uma atividade obrigatória que oferece a possibilidade de novos tipos de relações recíprocas, baseadas na responsabilidade comum.

Analisemos uma situação vivenciada na instituição:

Após várias tentativas frustadas de resolução de um exercício proposto pela professora, Globeleza possuía um semblante triste e desmotivado. Tal situação perdurou até o momento do intervalo deixando a menina desinteressada pela atividade. No entanto, após o retorno do intervalo, com ajuda da professora, Globeleza conseguiu resolver a situação proposta pela professora. A resolução do problema gerou na menina felicidade e seu semblante demonstrava um certo ar de confiança. Dizia a seus companheiros: "Viu como eu fiz, agora eu sei". (DIÁRIO DE CAMPO, 13/09/2012)

Como podemos perceber, diante dessas transformações e exigências sociais que a criança vivencia na escola surgem alguns casos típicos de dificuldades educativas que não acontecem na etapa de ensino anterior.

Por conseguinte, os problemas da aprendizagem escolar não são só questões da formação e do desenvolvimento intelectual da criança, mas também compreende aspectos da formação de sua personalidade em contato com o ambiente social. Nessa perspectiva, Vigotski (2003) infere que estar preparado para a escola significa, antes de tudo, saber generalizar e diferenciar as diferentes categorias dos objetos e fenômenos do mundo circundante.

Para Bozhovich (2003), a internalização de qualquer conteúdo evidencia a presença na criança da capacidade de distinguir e de fazer objeto de sua consciência aqueles fenômenos da realidade cujo conhecimento deve assimilar.

A respeito da pertinência da atividade de estudo no trabalho pedagógico junto as crianças de seis anos, Davidov (1988), que analisou o contexto de antecipação da escolarização aos seis anos de idade pela Reforma Escolar em 1984 na Rússia, não deixa dúvidas quanto a possibilidade de introduzir esse tipo de atividade na educação de crianças dessa faixa etária. Para o autor (2003), a distinção entre pensamento empírico e pensamento teórico está ligado a efetivação do princípio do caráter científico que, consequentemente está internamente ligado com a mudança do tipo de pensamento, projetada por todo o sistema de ensino. Desse modo, diferentemente do pensamento empírico que tem caráter externo, imediato, as representações gerais estão ligadas 
diretamente com a atividade prática, e os dados são obtidos através da atividade sensorial das pessoas.

Ante ao exposto, Davidov (2003) sublinha que a atividade de estudo dos escolares se estrutura em correspondência com o procedimento de exposição dos conhecimentos científicos e com o procedimento de promoção do abstrato ao concreto. Na visão do autor

El pensamiento de los alumnos, en el proceso de la actividad de estudio, tiene algo en comúm con el pensamiento de los científicos, quienes exponen los resultados de sus investigaciones por medio de las abstracciones y generalizaciones sustanciales y los conceitos teóricos que funcionan en el proceso de ascensión de lo abstacto a lo concreto. (2003, p. 212)

Davidov (2003) ratifica que as crianças ao iniciar a assimilação de qualquer disciplina científica, com a ajuda do professor, analisam o conteúdo do material, identificam algumas relações gerais iniciais, descobrindo simultaneamente que os fenômenos se manifestam em muitas outras relações particulares existente no material estudado. Conforme os alunos fixam, por intermédio dos signos, a relação geral inicial separada, as crianças constrõem a abstração substancial do objeto estudado.

De acordo com o autor (2003), na continuação da análise de tal material os alunos descobrem uma certa vinculação regular da relação inicial com suas diferentes manifestações e, assim, apropriam a generalização substancial do objeto estudado.

Dessa maneira, embora a atividade de estudo realizada pelas crianças pequenas demonstra-se em correspondência com o procedimento de exposição dos conteúdos da cultura humana elaborada historicamente, dentro desta atividade se mantém de forma peculiar, as situações e as ações que eram inerentes ao processo de criação real de tais produtos, devido ao procedimento de sua obtenção se reproduzir abreviadamente na consciência individual dos escolares. Assim, durante o cumprimento sistemático da atividade de estudo, se desenvolvem nos alunos, junto com a assimilação dos conhecimentos teóricos, a consciência e o pensamento teórico.

Dessa forma, iniciado desde Vigotski (2003), o centro de gravidade do entendimento da preparação intelectual da criança para o ensino escolar foi transposto da bagagem de ideias aos modos do pensamento infantil e ao nível de concientização e generalização de sua percepção da realidade. No entanto, as investigações (Davidov, 1988; Davidov, 2003; Vigotski, 2003; Bozhovich, 2003; Mukhina 1995; Domínguez, 2003) demonstram que o problema da distinção da tarefa de estudo e sua transformação no objeto independente da atividade do aluno, exige da criança que ingressa na escola não só um determinado nível de desenvolvimento intelectual, mas também o 
de sua atitude cognoscitiva em relação a realidade, isto é, um nível determinado do desenvolvimento de seus interesses cognoscitivos.

No bojo dessa discussão, quando se examina o processo de formação nos escolares de menor idade, da atividade de estudo, aparecem determinadas questões que merecem e requerem reflexões: a especificidade dos componentes estruturais (necessidades, motivos, tarefas, ações e operações) da atividade de estudo; as suas interrelações com outros tipos de atividade; a transição da brincadeira de papéis sociais para tal atividade; as etapas de seu desenvolvimento no curso da infância escolar.

\section{CONSIDERAÇÕES FINAIS}

Ao encerrarmos esta pesquisa sobre as manifestações das crianças de seis anos que ingressam no primeiro ano do Ensino Fundamental, sob o prisma do Enfoque Histórico-Cultural, entendemos, com base na apreensão do conjunto da exposição realizada até aqui, que podemos tecer várias análises e inferências sobre a implementação da proposta de expansão desse nível de ensino e suas implicações na vida da criança.

O material teórico e as análises das manifestações das crianças produzido sobre a atividades de estudo, tecido segundo os pressupostos e as opções metodológicas do enfoque supra citado, oferecem indicadores suficientes sobre a natureza social da origem destas esferas de ação humana, tanto do ponto de vista filogenético, quanto do ponto de vista ontogenético. Tal concepção disponibiliza análises substanciais sobre o desenvolvimento das diferentes manifestações da crianças no estudo, atravessado por alterações e incrementos em outras dimensões de desenvolvimento infantil, em especial a linguagem, a imaginação, a regra e indubitavelmente as relações com o outro, que precisam estar presentes em toda a trajetória de formação humana do sujeito.

A pesquisa se empenhou, portanto, com a busca de condições sociais concretas, que interferem e modulam as transformações dos processos psíquicos e atividades humanas. Nesse contexto, a mudança da condição social da criança de seis anos que antes pertencia ao universo da Educação Infantil tornou-se um importante tema de investigação para a compreensão da inserção da criança no Ensino Fundamental no sexto ano de vida.

Ao procurar entender as manifestações das crianças em relação ao estudo, compreendemos que para as crianças o ingresso em um espaço com mais exigências gera alguns desconfortos e dificuldades de fruição nas atividades de estudo, uma vez que as condições sociais desse local tornam-se diferente daquele vivenciado outrora por elas na educação infantil. Por 
outro lado, os episódios apresentados nesta pesquisa demonstram que o estudar, para as crianças, tem como objetivo auxiliar na compreensão do mundo e por este motivo torna-se uma atividade extremamente importante em sua vida.

Nessa direção, o professor do primeiro ano precisa organizar o processo educativo de forma integrada, respeitando igualmente os aspectos da atividade lúdica e das atividades de estudo, atendendo as especificidades e os modos de agir das crianças. Considerar esta pressuposições, auxilia a atuação sobre a zona de desenvolvimento proximal infantil, considerando, sobremaneira, as atividades e os conteúdos essenciais à aprendizagem, buscando alcançar o pleno desenvolvimento das faculdades humanas das crianças.

\section{REFERÊNCIAS}

BORONAT, M. E. Formación de las premisas del juego de roles em el tercer año de vida. In: GOMÉZ, A. M. S. et al. Estudio sobre las particularidade del dessarrolo del niño preescolar cubano. La Habana, Pueblo y Educación, 2002.

BOZHOVICH, L. El problema de la preparación del niño pra el aprendizaje escolar. In: IZNAGA, A. L. S.; CAMPO, G. A. M.; PÉREZ, M. E. R. Psicología del desarrolo del escolar: selección de lecturas. La Habana, Félix Varela, 2003.

. Lei no. 11.274/2006. Altera a redação dos artigos 29, 30, 32 e 87 da Lei no. 9.394, de 20 de dezembro de 1996. Diário Oficial [da] República Federativa do Brasil, Brasília, DF, 2006. Disponível em: <http://www.planalto.gov.br. Acesso em: 05 ago. 2010.

DAVIDOV, V. Problemas del desarrollo psíquico de los niños. In. La enseñanza escolar el desarrollo psiquico. Moscú: Editorial Progresso, 1988.

DAVIDOV, V. Contenido y estructura de la actividad de estudio. In: IZNAGA, A. L. S.; CAMPO, G. A. M.; PÉREZ, M. E. R. Psicología del desarrolo del escolar: selección de lecturas. La Habana, Félix Varela, 2003a.

DAVIDOV, V. El estudio como actividad en el escolar pequeño. In: IZNAGA, A. L. S.; CAMPO, G. A. M.; PÉREZ, M. E. R. Psicología del desarrolo del escolar: selección de lecturas. La Habana, Félix Varela, 2003b.

DOMínGUEZ, L. Edad escolar. In: IZNAGA, A. L. S.; CAMPO, G. A. M.; PÉREZ, M. E. R. Psicología del desarrolo del escolar: selección de lecturas. La Habana, Félix Varela, 2003.

ELKONIN, D. B. Psicologia do jogo. São Paulo: Martins Fontes, 1998.

MELLO, S. A. Infância e humanização: algumas considerações na perspectiva histórico-cultural. In: PERSPECTIVA, Florianópolis, v. 25, n. 1, 83-104, jan./jun. 2007.

MUKHINA, V. Psicologia da idade pré-escolar. São Paulo: Martins Fontes, 1995, 324 p. 
VIGOTSKY, L. S. La crisis de los siete años. In: IZNAGA, A. L. S.; CAMPO, G. A. M.; PÉREZ, M. E. R. Psicología del desarrolo del escolar: selección de lecturas. La Habana, Félix Varela, 2003. 